\title{
Integration of Optical Fiber and Optoelectronic Devices
}

\author{
John V. Badding, Pier J.A. Sazio, Venkatraman Gopalan, Anna C. Peacock, Noel Healy, Justin Sparks, \\ Mahesh Krishamurthi \\ Departments of Chemistry and Materials Science and Engineering, Pennsylvania State University, University Park, \\ PA 16801, USA \\ Optoelectronics Research Centre, University of Southampton, Highfield Campus, S017 1BJ, United Kingdom \\ jbadding@chem.psu.edu
}

\section{Introduction}

There is much current interest in integrated nanophotonics, as evidenced by the large amount of literature regarding silicon photonics, integration of direct bandgap semiconductors onto silicon chips, and related topics. Our group has been pursing a different, potentially complementary vision of all-fiber optoelectronics in which light can be generated, modulated, and detected within the fiber itself ${ }^{[1-5]}$. Fiber devices are in general valued for their robustness, simplicity, and ability to integrate seamlessly with existing fiber infrastructure. If the light never leaves the fiber, for example, difficulties associated with modal and impedance mismatches between fibers and planar semiconductor waveguides do not need to be overcome. Fiber lasers also integrate naturally with fibers, whereas using direct gap semiconductor lasers on chip remains an ongoing challenge.

\section{Semiconductor Fiber Fabrication}

All-fiber optoelectronics will require the ability to generate, transmit, modulate, and detect light within a fiber. Our group has thus focused on increasing the range of materials that can be integrated into optical fibers, as well as demonstrating new semiconductor junction-fiber hybrid devices. Conventional fiber drawing is thus far largely not
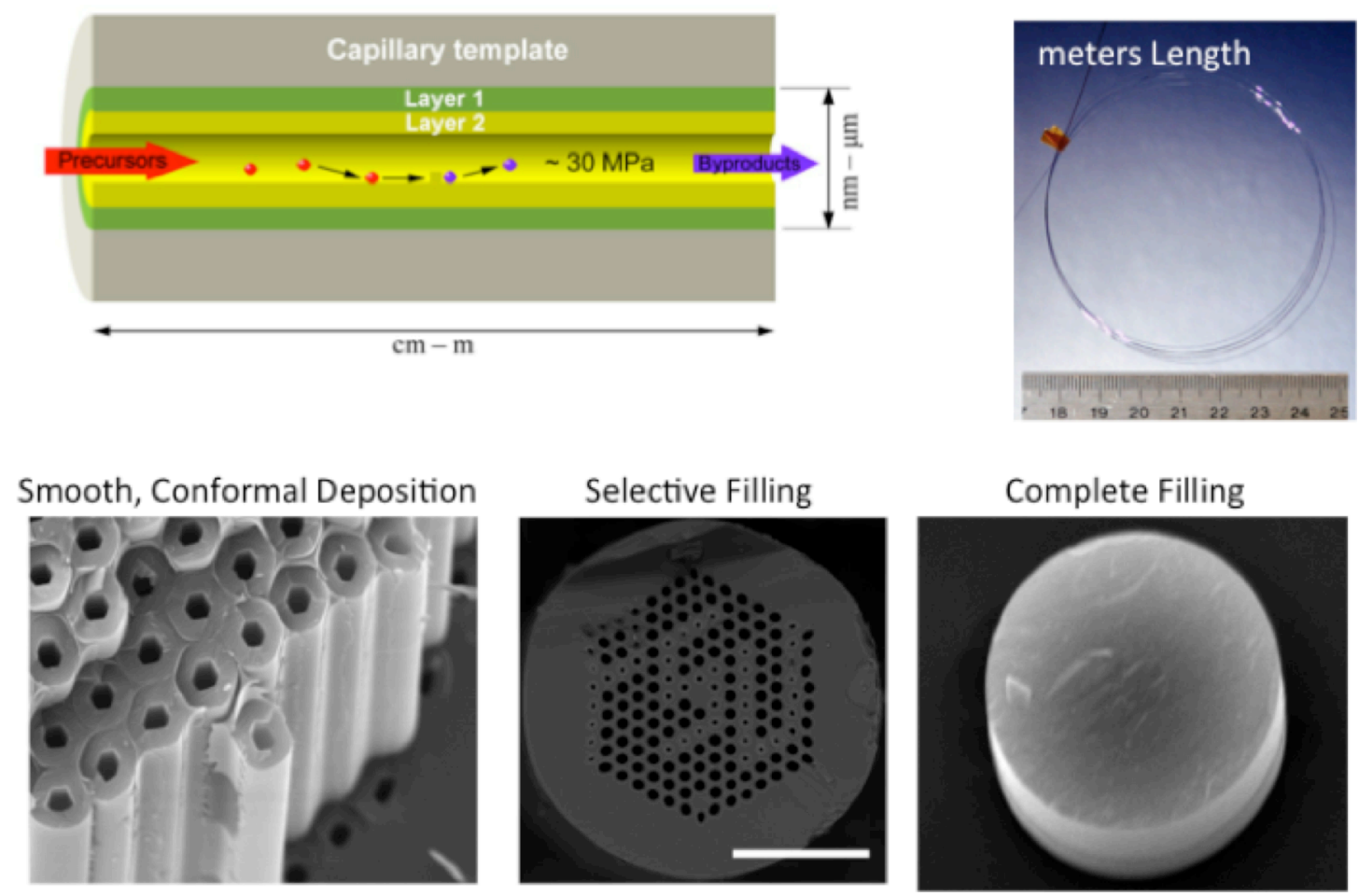

Figure 1. High pressure chemical vapor deposition allows for the deposition of conformal, well developed films of semiconductors, in this case, silicon, within the pores of microstructured optical fibers. Smooth silicon films that conformally coat a MOF template o form $2 \mu \mathrm{m}$ diameter tubes are possible, along with selective filling of a template, and complete filling of the pores over distances of many centimeters, to form void-free atomically smooth fiber cores, long enough for many semiconductor fiber devices. Recent work shows that silicon films as long as 10 meters are possible, with prospects for much longer lengths in the future. 
compatible with the materials of modern optoelectronics, namely unary group IV semiconductors and compound semiconductors. Thus our group has developed a new technique, high pressure chemical vapor deposition (Figure 1) that allows for the incorporation of these materials into the pores of microstructured optical fibers (MOF). A single pore or an array of pores in an optical fiber is treated as a micro to nanoscale deposition chamber upon which deposition can occur. An advantage of this approach is that it should be possible to deposit nearly all of the materials that are deposited in conventional chemical vapor deposition reactors within optical fibers. Thus far we have deposited well-developed fiber cores of both group $\operatorname{IV}^{[1,2,5]}$ and compound semiconductors ${ }^{[3]}$. In general, high pressure precursors are configure to flow down the pores of an MOF (Figure 1). Heating of the MOF allows for smooth conformal deposition of layers of silicon and other semiconductors ${ }^{[1,2]}$. Selected filling of the pores is possible as well as complete filling that allows for nearly atomically smooth wires that form well-developed silicon fiber cores. The non-linear optical properties of these silicon fibers have been under investigation ${ }^{[6-11]}$.

\section{Adding Optoelectronic Function to Fibers}

Using the capabilities for fabricating layers of doped semiconductors via high pressure chemical deposition, we have made GHz bandwidth rectifying Schottky junctions in the pores of microstructured optical fibers ${ }^{[1]}$. Layers of doped semiconductors and metals have been deposited sequentially in the fiber pores (Figure 2). The light guiding characteristics of these waveguiding junctions have been investigated after Pt electrodes were fabricated on one end. Illumination in the waveguiding geometry reveals that the junctions can have $3 \mathrm{GHz}-3 \mathrm{~dB}$ bandwidth (Figure 2). These structures represent the first examples of junctions constructed in optical fibers from crystalline, welldeveloped semiconductors. Integration of junctions with built-in electrical potential into optical fibers to form detectors represents a first step towards integrating many other functions associated with optoelectronic junctions into optical fibers. Modulators, higher performance waveguiding detectors, and even diode lasers may ultimately become possible by means of this high pressure chemical deposition approach.
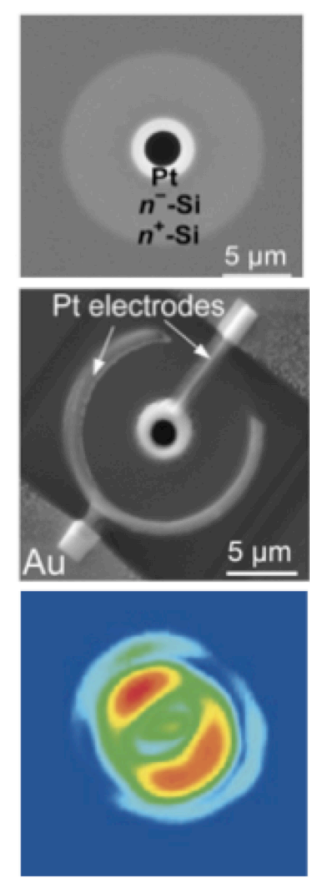

Figure 2. SEM micrograph of cross section of fiber integrated GHz Bandwidth silicon Schotty junction. These junctions guide light in the higher index undoped region, as shown in the far-field image of light exiting the junction. The junction functions with $3 \mathrm{GHz}-3 \mathrm{~dB}$ bandwidth. 
Low loss zinc selenide core optical fibers have also been fabricated by high pressure chemical vapor deposition ${ }^{[3]}$. These fibers are particularly useful for infrared applications at wavelengths out to $16 \mu \mathrm{m}$. The non-linear optical properties of these waveguides are under investigation, along with their utility for high resolution infrared imaging in the form of tapered arrays of fiber cores ${ }^{[12]}$. We have also developed $\mathrm{Cr}$ doped $\mathrm{ZnSe}$ fiber lasers fabricated by high pressure CVD.

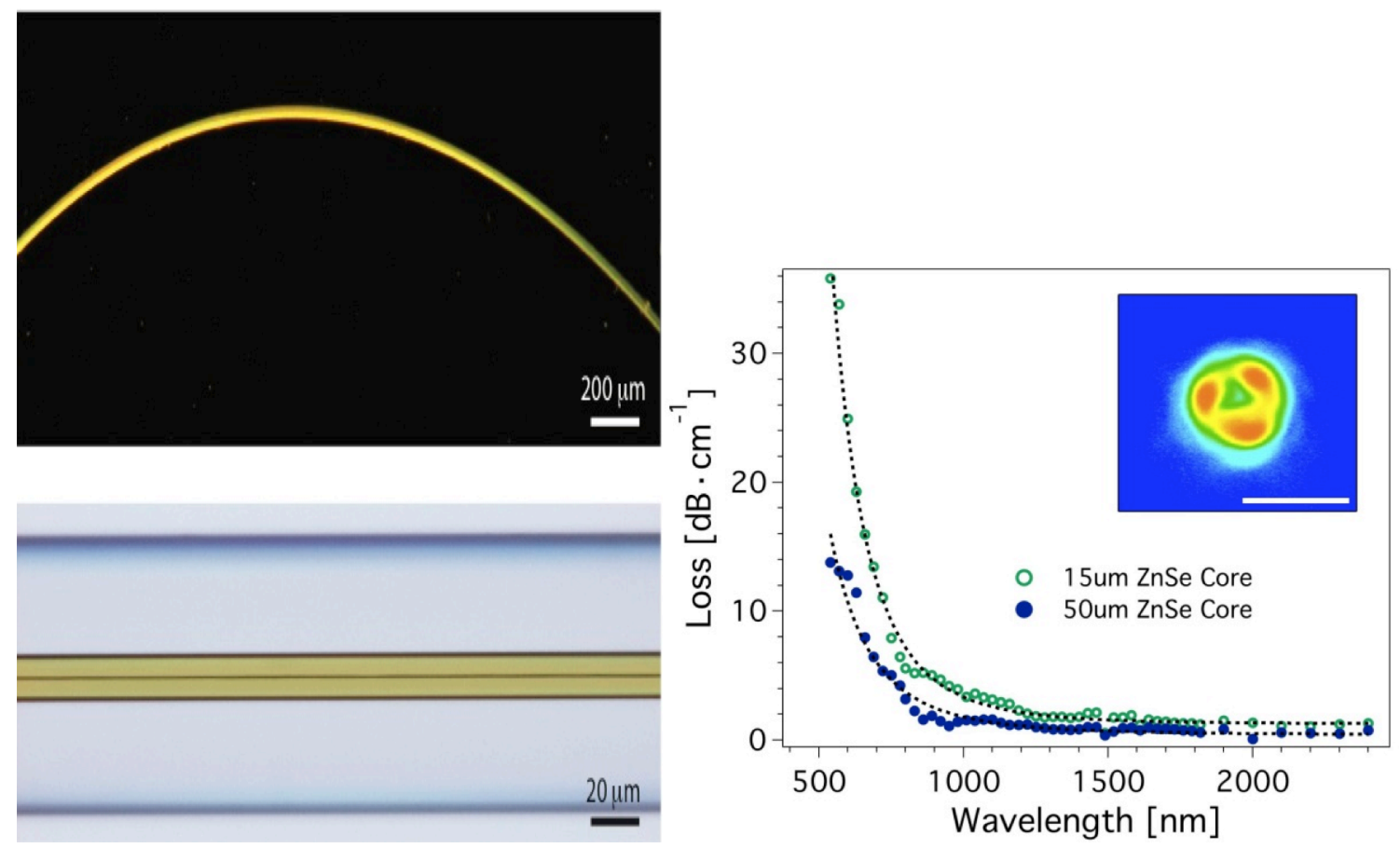

Figure 3. Optical micrographs of zinc selenide Optical Fibers fabricated by high pressure chemical vapor deposition have losses as low as $0.5 \mathrm{~dB} / \mathrm{cm}$, in the range of losses for many planar semiconductor waveguides.

\section{References}

[1] R. R. He, P. J. A. Sazio, A. C. Peacock, N. Healy, J. R. Sparks, M. Krishnamurthi, V. Gopalan, J. V. Badding, Nat. Photonics 2012, 6, 174.

[2] P. J. A. Sazio, A. Amezcua-Correa, C. E. Finlayson, J. R. Hayes, T. J. Scheidemantel, N. F. Baril, B. R. Jackson, D. J. Won, F. Zhang, E. R. Margine, V. Gopalan, V. H. Crespi, J. V. Badding, Science 2006, $311,1583$.

[3] J. R. Sparks, R. R. He, N. Healy, M. Krishnamurthi, A. C. Peacock, P. J. A. Sazio, V. Gopalan, J. V. Badding, Adv. Mater. 2011, 23, 1647.

[4] I. A. Temnykh, N. F. Baril, Z. W. Liu, J. V. Badding, V. Gopalan, Opt. Express 2010, 18, 5305.

[5] N. F. Baril, B. Keshavarzi, J. R. Sparks, M. Krishnamurthi, I. Temnykh, P. J. A. Sazio, A. C. Peacock, A. Borhan, V. Gopalan, J. V. Badding, Adv. Mater. 2010, 22, 4605.

[6] N. Vukovic, N. Healy, P. Mehta, T. D. Day, P. J. A. Sazio, J. V. Badding, A. C. Peacock, Appl. Phys. Lett. 2012, 100 .

[7] P. Mehta, N. Healy, T. D. Day, J. R. Sparks, P. J. A. Sazio, J. V. Badding, A. C. Peacock, Opt. Express 2011, 19, 19078.

[8] N. Vukovic, N. Healy, P. Horak, J. R. Sparks, P. J. A. Sazio, J. V. Badding, A. C. Peacock, Appl. Phys. Lett. $2011,99$.

[9] P. Mehta, N. Healy, N. F. Baril, P. J. A. Sazio, J. V. Badding, A. C. Peacock, Opt. Express 2010, 18, 16826.

[10] L. Lagonigro, N. Healy, J. R. Sparks, N. F. Baril, P. J. A. Sazio, J. V. Badding, A. C. Peacock, Appl. Phys. Lett. 2010, 96.

[11] N. Healy, J. R. Sparks, M. N. Petrovich, P. J. A. Sazio, J. V. Badding, A. C. Peacock, Opt. Express 2009, $17,18076$. 
[12] M. Krishnamurthi, J. R. Sparks, R. He, I. A. Temnykh, N. F. Baril, Z. Liu, P. J. A. Sazio, J. V. Badding, V. Gopalan, Opt. Express 2012, 20, 4168. 